\title{
Postpartum corticosteroids in HELLP syndrome - standard to prompt recovery
}

\author{
Gabor M , Drab M, Holoman K \\ 2nd Department of Obstetrics and Gynaecology, University Hospital Bratislava, Comenius University, \\ Bratislava, Slovakia. martingabormd@gmail.com
}

\begin{abstract}
OBJECTIVES: To perform a complex review of HELLP syndrome and its treatment from up to date scientific literature. Study of the interresting treatement regime of the patient.

METHODS: Complex analysis of the syndrome, systematic search of medical scientific databases and Slovak Medical Library. Analysis of the life threatening state of the patient, retrospective analysis of the diagnostics, treatment, acute management, complications and clinical results.

RESULTS: According to up to date literature and our good clinical experiences we can encourage the use of high-dose corticosteroid therapy in HELLP syndrome.

CONCLUSION: The most recent studies definitely recommend the high dose corticosteroid treatment in recovery management by the HELLP syndrome. We have used the high-dose corticosteroid regime as a recovery management for the patient with postpartum HELLP with very good clinical and laboratory response followed by prompt recovery of the patient and without other complications. We want to support and empasize the indication of the Dexamethasone regiment by HELLP, becouse the clinical experiences with this treatment are not well-known and usually the corticosteroids are not given to the patients with HELLP, or the treatment is "daemonized". Our clinical experience with this treatment was successful and the patient definitely profited of it. We support the opinion, that the benefit of described regiment highly exceedes the possible adverse effects of the therapy (Fig. 8, Ref. 61). Text in PDF www.elis.sk.

KEY WORDS: HELLP syndrome, corticosteroids, complications, postpartum, recovery.
\end{abstract}

\section{Introduction}

The HELLP syndrome is a serious complication in pregnancy characterized by 3 components - haemolysis, elevated liver enzymes and low platelet count. It is currently regarded as a variant of severe preeclampsia or as its complication $(1,2,3)$. The causal therapy is only termination of the pregnancy. Although rare, the complication despite the standard treatment can leat to life threatening condition of the patient. The high dose corticosteroids regimes applied in HELLP patients were also described as controversial, and unfortunatelly the guidelines are not very clear by meaning of the application of this regiments. In the article the complex review of HELLP syndrome an its management is discussed, following the critical discussion of clinical application of the high dose corticosteroid regiments in the recovery management of the patients with HELLP. Usually there is no standard treatment in meaning the corticosteroids application by HELLP, but some regimes were successfully used in prompt recovery of the patients, especially in postpartum and complicated cases.

2nd Department of Obstetrics and Gynaecology, University Hospital Bratislava, Comenius University, Bratislava, Slovakia

Address for correspondence: M. Gabor, MD, PhD. University Hospital Bratislava, Ruzinovska 6, SK-826 09 Bratislava, Slovakia.

Phone: +421.903818357
With the publicated manuscript we want to support and empasize the indication of the discussed Dexamethasone regiment by HELLP, becouse the clinical experiences with this treatment are not well-known and usually the corticosteroids are not given to the patients with HELLP, or the treatment is "daemonized". Our clinical experience with this treatment was successful and the patient definitely profited of it. We support the opinion, that the benefit of described regiment highly exceeds the possible adverse effects of the therapy.

\section{Pathogenesis and diagnosis of the HELLP}

The syndrome can be presented as a complete or incomplete form. The diagnosis of the complete form is based on the presence of all 3 major components, but incomplete forms can be presented with only 1 or 2 components of the complete triad (4). The HELLP in its complete form is a serious condition and is associated with substantial risk for the mother and her foetus $(5,6)$. The minor fraction of HELLP is caused by the foetal homozygous LCHAD (Long-chain 3-hydroxyacyl-CoA dehydrogenase deficiency), but for the most cases, the genetic background has not yet been elucidated (7). The syndrome occurs in about 0.5 to 0.9 percent of all pregnancies and in 10 to 20 percent of cases of severe preeclampsia (8). Usually the syndrome develops before the delivery and the most cases were diagnosed between 27th and 37th week of the gestation (9). Postpartum HELLP syndrome usually develops 
within the first 48 hours after the delivery. The reported cases of the postpartum HELLP are also called ,the cases of lost battles“. Because of unexpectedness, suddenness and fulminant course and as well for absence of the clinical signs of preeclampsia, this syndrome can lightly confuse the physicians and obstetricians and can lead to diagnostic delay (10)

Although variable, the typical onset of the syndrome is rapid (11). The majority of the diagnosed cases were preceded by preeclampsia, hypertension, proteinuria, excessive weight gain or generalized oedema (12).

Women with the incomplete syndrome develop usually less complications than those with the complete forms. Partial form can develop to a complete form and also, although rare, partial or total reversal of the complete triad can occasionally occur (13). Typical clinical symptoms of the syndrome include right abdominal upper quadrant pain or epigastric pain, nausea and vomiting. The pain may be fluctuating and "colic-like”. Typically the patient reports malaise or "flu-like" symptoms before the onset (14). Headache and visual symptoms are also common. Some authors reported exacerbation during the night and recovery state during the day (15) Jaundice as the first symptom of HELLP was also reported (16). The use of new markers of HELLP could lead in the future to better prediction or monitoring the patient. Increased serum concentration of circulating glycocalyx components as uncontrolled, exaggerated inflammatory response is the recently studied marker (17).

Haemolysis is caused in HELLP syndrome by a microangiopathic haemolytic anaemia. The present endothelial dysfunction leads to red cell fragmentation in small vessels and the verification of fragmented red cells called schizocytes in the peripheral blood smear is very suspicious (18). Also, the compensatory release of immature reticulocytes can occur. Destruction of the red blood cells caused by haemolysis leads to increased serum lactate dehydrogenase levels (LDH) and decreased haemoglobin concentration. Haemoglobinuria can be macroscopically recognizable (19). Liberated haemoglobin is converted to unconjugated bilirubin, which leads to its increased plasma levels, or it may be bound in the plasma by haptoglobin. Low haptoglobin concentration (lower than $1 \mathrm{~g}$ per $\mathrm{L}$ to lower than $0.4 \mathrm{~g}$ per $\mathrm{L}$ ) is the preferred marker of haemolysis. Elevation of liver enzymes may also reflect the haemolytic process. Enhanced aminotransferases AST and ALT are mostly due to a liver injury. More sensitive indicator for acute liver damage is plasma glutathione S-transferase-a1 (GST) (20). Thrombocytopaenia ( Platelets less than $150.10^{9}$ per L) can be generally caused in the pregnancy by gestational thrombocytopaenia, immune thrombocytopaenic purpura, preeclampsia or HELLP syndrome. Platelets under $100.10^{9}$ per $\mathrm{L}$ are relatively rare in preeclampsia and gestational thrombocytopaenia, frequent in ITP and obligatory in the HELLP. In the HELLP syndrome, the thrombocytopaenia is due to an increased consumption (21).

\section{Diagnostic criteria}

There are two definitions for diagnosing the HELLP syndrome - Tenessee and Mississippi classification. The Tenessee system proposed strict criteria for the complete syndrome - intravascular haemolysis diagnosed by abnormal peripheral blood smear, increased serum bilirubin more than 20.5 umol per L and elevated LDH levels more than 600 units per L. The Mississippi classification is the triple class system based on the nadir platelets count during the disease. Class I and II is associated with haemolysis (LDH more than 600 units per L) and elevated AST (more than $70 \mathrm{U} / \mathrm{L}$ ), while class III requires only LDH levels more than 600 units per $\mathrm{L}$ and AST more than 40 in addition to the specific PLT count in the interval 100 to $150.10^{9}$ per $\mathrm{L}(22,23)$.

\section{Differential diagnosis}

In differential diagnosis, there is necessary to differentiate the diseases that may mimic HELLP, such as viral hepatitis, cholangitis, idiopathic or thrombotic thrombocytopaenic purpura (ITP, TTP), acute fatty liver in pregnancy, heamolytic uremic syndrome (HUS) and systemic lupus erythematosus (SLE) (24). In case of fatty liver of pregnancy, hypertension and proteinuria are usually absent. Hypoglycaemia and prolongation of protrombin time may distinguish acute fatty liver from the HELLP (25). Computerized tomography, ultrasound examination or biopsy of the liver can be also useful in differential diagnosis (24). Pregnancy can exacerbate the pre-existing ITP, but it doesn't increase its incidence (25). HUS and TTP are other thrombotic microangiopathies. In the HUS, the microvascular injury affects mainly the vessels in kidneys and is presented with symptoms of renal failure (1). TTP is an extremely rare condition during the pregnancy and is frequently presented as neurological abnormalities - e.g. headache, aphasia, transient paresis, confusion or seizures (24). The mortality of the HUS and the TTP has been decreased due to the use of plasma exchange and intensive care (26). The clinical findings in SLE can be very various and multi organ disorder is typical. The clinical signs and laboratory findings by the lupus nephritis can be similar to those with severe preeclampsia. Antiphospholipid and anti dsDNA antibodies are usually present (27). In the differential diagnosis, also the folate deficiency during the pregnancy can mimic the incomplete HELLP. Folate deficiency during the pregnancy is common, but its progression to megaloblastosis, haemolytic anaemia, thrombocytopaenia and coagulopathy is extremely rare (28).

\section{Complications of the HELLP syndrome}

The main maternal complications in HELLP are eclampsia, placental abruption, disseminate intravascular coagulopathy (DIC), acute renal failure, ascites, cerebral and pulmonary oedema, wound haematoma, liver rupture and sub capsular liver haematoma, hepatic failure, cerebral infarction or haemorrhage, retinal detachment and maternal death. The foetus is threatened by perinatal death, IUGR (intrauterine growth retardation), preterm delivery, neonatal thrombocytopaenia and respiratory distress. The laboratory parameters that predict more than 75 percent of complications are LDH concentration over $1400 \mathrm{U}$ per L, AST more than 150 U per L, ALT over 100 U per L, uric acid concentration over $460 \mathrm{umol} / \mathrm{L}$. The typical clinical symptoms of HELLP such as headache, visual changes, epigastric pain, nausea and vomiting have been suggested to be better predictors of adverse outcome of the syndrome (14). Recent studies recommend computerized tomography evaluation by the presence of epigastric pain of the 
patients with this syndrome (29). Few cases of HELLP with multiple complications were also described (11).

\section{Management of HELLP}

There are three major modalities of the management of HELLP. Immediate delivery as the primary choice at 34 weeks gestation or later, delivery within 48 hours after evaluation, stabilisation of the maternal clinical condition and corticosteroids treatment in cases 27th to 34th weeks of gestation, or expectant conservative management for more than 48 hours before 27th weeks (30).

After the diagnosis, the next step is to stabilize the maternal clinical conditions with intravenous fluids, antihypertensive drugs and magnesium sulphate to prevent convulsions.

The advantages of a limited prolongation of the pregnancy should be carefully weighted against the increased risk of maternal and foetal complications like placental abruption, acute renal failure, pulmonary oedema, DIC etc. If the maternal conditions alter, caesarean section is inevitable $(1,31,32,33)$. Some authors warn against conservative management and contraindicate it (34).

The indications for an emergent caesarean delivery is HELLP syndrome class 1 and 2, uncontrolled or worsening maternal conditions, developing signs of intrauterine foetal distress, blood pressure over 160/110 mmHg despite an adequate antihypertensive treatment, persisting or worsening clinical symptoms, deteriorating renal functions, ascites, placental abruption, oliguria, pulmonary oedema or eclampsia (35). The regional anaesthesia is contraindicated if the PLT count is below $100.10^{9}$, and platelets transfusion prior to caesarean section should be used. In case of vaginal delivery, platelets transfusion should be given by the PLT count below $25.10{ }^{9}$ per L (18).

The antihypertensive drugs should be administered to keep the blood pressure below 155/105mmHg and the patient must be strictly monitored in the first 48 hours after the delivery. In the pregnant women between 24 and 34 weeks, a full course of corticosteroids should be applied after maternal stabilisation (36). Corticosteroid treatment (CS) promote the foetal lung maturation, but the foetal lung must be biologically ready for this treatment to trigger it. The window of the biological readiness occurs between 26th and 34th weeks gestation (37). The Betamethasone use was more recommended as a drug of choice for the lung maturation, because it might be safer and more protective for the immature brain (38). The Cochrane update recommended in 2006 a single course of $12 \mathrm{mg}$ Betamethasone given in twice doses (39). The use of the multiple courses is controversial and may potentially harm the foetus. Increased incidence of the cerebral palsy and adrenal suppression of the neonates were described (40, 41, 42). Recent studies and analysis of Cochrane database reviews do not favour Dexamethason, nor Bethametasone in the management of HELLP and it is estimated, that only new studies can solve this dilemma (43). One study showed that Dexamethasone in respect to improve platelet count was superior to Betamethasone (44).

The use of corticosteroids in HELLP is not only about the standard use as „foetal lung maturation“. Maternal benefits of this treatment was first reported in 1984. The use of these drugs was associated with decreasing oedema, inhibiting the endothelial dysfunction, prevention of microangiopathic anaemia and inhibiting the cytokines activation in inflammatory response $(45,46)$.

The important mechanism by the use of CS treatment by the HELLP was described. Dexamethasone administration blunts and decreases antiangiogenic and inflammatory factors, which play the role by the pathophysiology of the HELLP (47).

Standard corticosteroids treatment has only minor clinical effects in HELLP, but high-dose Dexamethasone regimes using 10 mg Dexamethasone every 12 hours reduced maternal morbidity and induced more rapid improvement of the platelets count (46, $48,49,50)$. Some studies showed also controversial results and did not describe the benefits of corticoids in HELLP (51). In the summary, the single course of CS has documented the clinical benefit for the foetus without adverse effects. Multiple courses should be avoided (52). In the study of pospartum applied corticosteroids for an accelerated recovery from the HELLP syndrome, the scheme of intravenous Dexamethasone at 12 hours intervals $10 \mathrm{mg}-10 \mathrm{mg}-5 \mathrm{mg}-5 \mathrm{mg}$ over 36 hours was used. Patients assigned in the control group received no corticosteroids. There were described significant changes in mean arterial pressure, urinary output, platelet count, LDH, AST in the two reported groups. The corticosteroid treated patients recovered more rapidly from the disease, than did the control group. The authors postulate, that use of this therapeutic scheme could result in lessened overall maternal morbidity and mortality, shorter intensive care units hospitalization and overall hospitalization with reduced medical care costs (53). As a case report, also the use of Methylprednisolon by HELLP syndrome was described. Schlembach et al used $40 \mathrm{mg}$ Methylprednisolon given to the patients with HELLP in 25th week of gestation once a day. Authors described good and very prompt effects on stabilisation of the mother and ability of prolongation of this pregnancy for 33 days (54). In other treatment options of HELLP, the use of antithrombin may correct hypercoagulability, stimulate prostacyclin production, regulate thrombin induced vasoconstriction, improve foetal status in foetal biophysical profile and promote foetal growth (55).

\section{Postparum management}

It was described, that one third of HELLP develop in the first 48 hours after delivery (4). The complications as pulmonary oedema or renal failure were here significantly increased in comparison with the antenatal onset of the HELLP (56). Early post-partum administration of high dose corticosteroids might accelerate recovery (57). As the routine regime should be given $10 \mathrm{mg}$ dexamethasone every 12 hours (58). Some recent studies did not encourage the postpartum Dexamethasone use and, on the contrary, they described no significant difference in maternal morbidity and mortality, in the duration of hospitalisation and the need of administering blood products. The linear model adjustments showed in this studies no significant differences between „medicated“ and „placebo“ groups in duration of platelets count recovery, AST, LDH, haemoglobin levels or recovery of diuresis (59). Finally, the most recent results described relevant benefits of the CS treatment by HELLP syndrome. 
Women with the HELLP syndrome and post-partum progressive elevation of bilirubin and creatinine may benefit from plasma exchange with fresh frozen plasma (60). By the signs of worsening and continuing haemolysis, trombocytopaenia and hypoproteinaemia, adequate erythrocyte, thrombocyte and albumin supplementation should be given in standard regimens (12, 18). Heparins and antithrombine should be administered for the patients with coagulopathy, DIC complications and preeclampsia-eclampsia (61, 33).
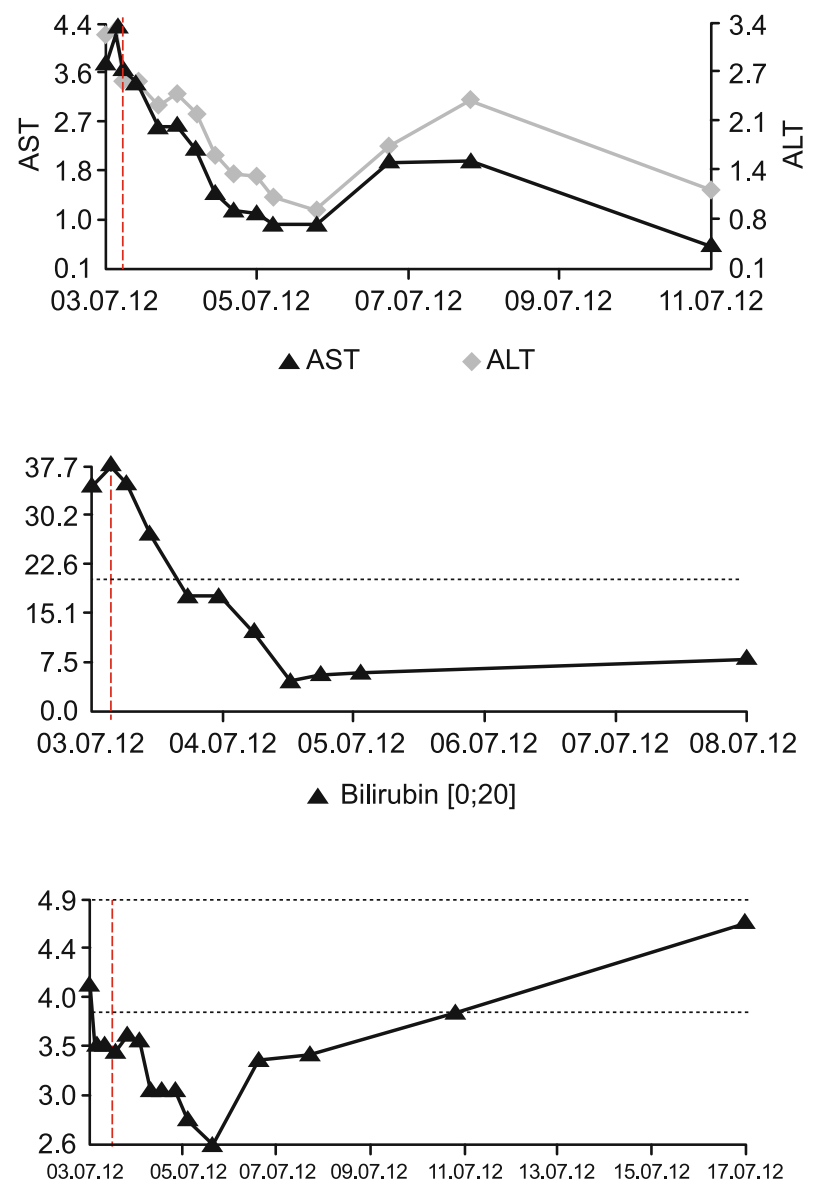

A Erythrocytes [3.8;4.9]

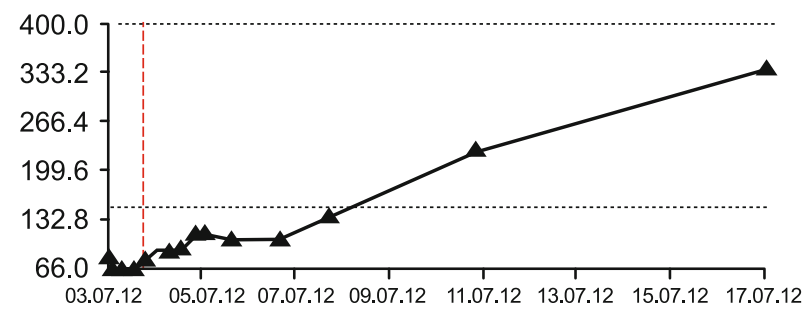

A Thrombocytes [150;400]
Case report of post-partum CS recovery management

27 years old primigravida with gestational diabetes well compensated on diet, without the history of other complication during the pregnancy was admitted to the hospital to the materno-fetal medicine department in the 35th week. The complaints of the patients were about decreasing frequency of the foetal movements. By the standard ultrasound biometry, the disproportion of foetal growth was diagnosed (Abdominal circumference - 5 weeks), Doppler velocimetry described pathological flow in the

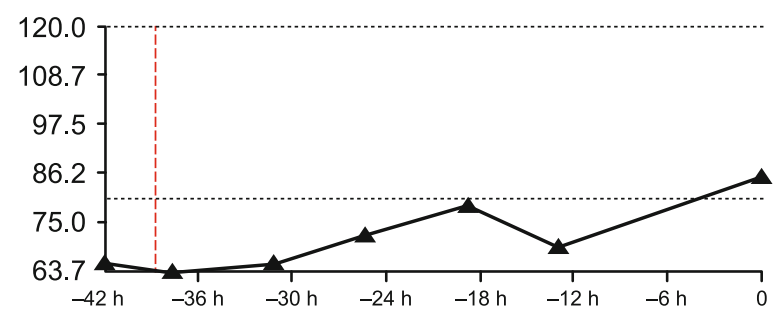

A Antithrombine III $[80 ; 120]$

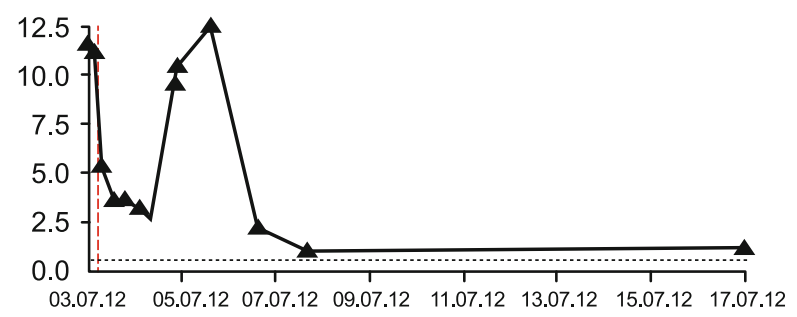

D Dimers [0;0.55]
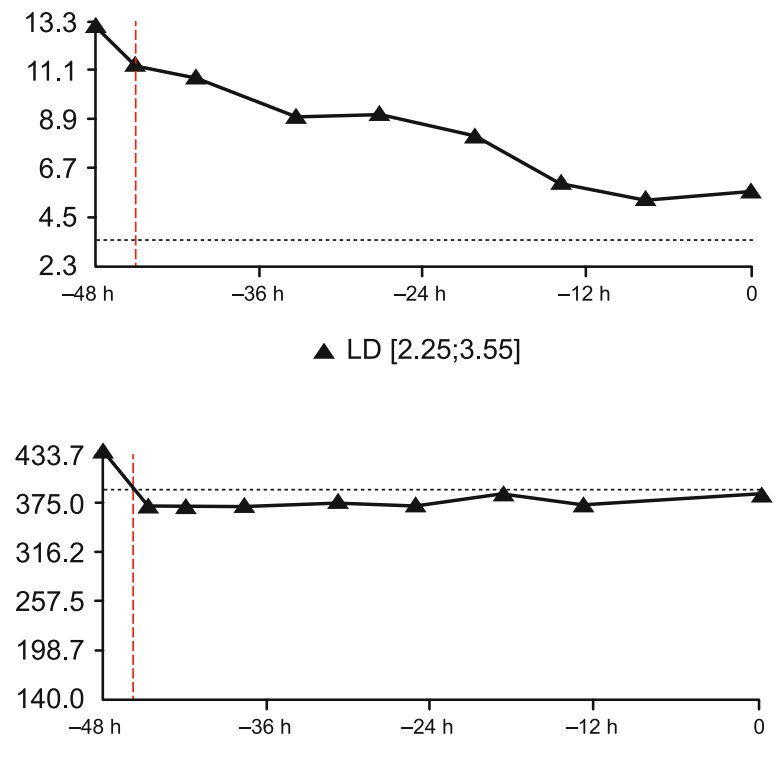

A Uric acid [140;390]

Figures 1-8. Dynamics of the laboratory tests during the corticosteroid treatment of HELLP - ALT and AST ( $\mu \mathrm{kat} / \mathrm{L})$, Bilirubine $(\mu \mathrm{mol} / \mathrm{L})$, Erythrocytes $\left(\mathbf{x 1 0}^{12} / \mathrm{L}\right)$, Thrombocytes $\left(\mathbf{x 1 0}^{9} / \mathrm{L}\right)$, Antithrombine III (\%), D-dimers $(\mu \mathrm{mol} / \mathrm{L}), \mathrm{LDH}(\mu \mathrm{kat} / \mathrm{L})$ and uric acid $(\mu \mathrm{mol} / \mathrm{L})$. Red vertical line defines the time of first dose of the Dexamethasone regime " $10-10-5-5$ " given every 12 hours intravenously. 
418-424

umbilical artery - amputation of the diastolic flow. Blood pressure and laboratory tests were normal. After the diagnostics, an acute caesarean section was indicated, the operation was carried out without complications or extensive perioperative blood loss. 2 hours later, we diagnosed hypertensive blood pressure 210/120 $\mathrm{mmHg}$, the patient complained about slight discomfort by the breathing, other clinical findings were negative. The laboratory tests described slight anaemia, severe trombocytopaenia, elevation of the liver function tests, hypoalbuminaemia and increased levels of the intravasculary hemolysis markers (Uric acid 368,7 umol/L, AST 4,42 ukat/L , ALT 3,37 ukat/L, ALP 1,44 ukat/L, LDH 13,31 ukat/L, PLT 66.10\%/L, D-dim 11,66 umol/L , HB 117 g/L, Alb 29 g/L). According to Mississippi classification, we supposed IIIrd grade HELLP syndrome. The patient was monitored in the intensive care unit, adequate antihypertensive therapy was administered (Methyldopum tbl. 3x250 mg p.o. and Urapidil titrated $100 \mathrm{mg}$ in $50 \mathrm{ml}$ with loading perfusion of $5 \mathrm{ml}$ per one hour), low molecular weight heparins prophylaxis was extended to therapeutic doses (12500 IU Enoxaparinum s.c.). The postpartum „recovery therapy“ scheme using high doses Dexamethason given intravenously every 12 hours was immediately started (10 $m g-10 m g-5 m g-5 m g$ every 12 hours. i.v.). Prevention of the gastric ulceration with Pantoprazol and regular control of glycemic profiles were also indicated.

After the administration of corticosteroids, the blood pressure normalised (ability to reduce the titration of Urapidil progressively from 5 to 4 and $3 \mathrm{ml}$ per one hour), the laboratory test in dynamics showed prompt recovery. The Figures $1-8$ show the dynamics of the results of laboratory tests during the treatment (ALT and AST, Bilirubine, Erythrocytes, Thrombocytes, Antithrombine III, D-dimers, LDH and uric acid ), red vertical line defines the time of first dose of the Dexamethasone.

In the intensive care unit, patient fluids input and output was strictly monitored, also the renal function parameters and coagulation were under control. Because of clinical signs and symptoms of anaemia ( $\mathrm{Hb} 77 \mathrm{~g} / \mathrm{L}$ ), transfusion of erythrocytes was administered. It was not necessary to substitute the patient with trombocytes, hypoproteinaemia was substituted with Albumin intravenously.

9 days after the operation, the patient complained about chest pain and breathing problems. CT pulmoangiography and echocardiography excluded embolisation to the pulmonary artery and only slight fluidothorax and fluidopericard was diagnosed. During the following management, the doses of LMWH were reduced. Physiological levels of the thrombocytes were reached 48 hours after the first administration of corticosteroids, 12 hours after this rescue treatment the blood pressure normalised, the liver function tests rapidly changed (50 percent decrease during first 24 hours, levels less than $1 \mathrm{mmol} / \mathrm{L}$ were described on the third day) and eight days after the start of the corticosteroids, physiological levels were diagnosed. The D-Dimers decreased in the first 24 hours, coagulation tests didn't worsen, uric acid levels and LDH also promptly normalized. The patient was discharged 23 days after the operation.

\section{Methods}

Complex analysis of the syndrome, systematic search of medical scientific databases and Slovak Medical Library. Analysis of the lifethreatening clinical case, retrospective analysis of the diagnostics, treatment, acute management, complications and clinical results.

\section{Results}

The most recent studies definitely recommend the high dose corticosteroid treatment in recovery management by the HELLP syndrome. We have used the high-dose corticosteroid regime as the recovery management for the patient with postpartum HELLP with very good clinical and laboratory response followed by a prompt recovery of the patient and without other complications. We want to support and emphasize the indication of the Dexamethasone regiment by HELLP, becouse the clinical experiences with this treatment are not well-known and usually the corticosteroids are not given to the patients with HELLP, or the treatment is "daemonized". Our clinical experience with this treatment was successful and the patient definitely profited of it. We support the opinion, that the benefit of described regiment highly exceedes the possible adverse effects of the therapy.

\section{Discussion}

Although some authors didn't describe clear benefits by corticosteroid treatment in HELLP syndrome, the majority of the studies recommend the use of high-dose corticosteroids given intravenously after delivery as the standard therapy. According to our good clinical experiences described in the article, we can encourage this opinion.

\section{References}

1. Sibai BM. Diagnosis, controversies and management of the syndrome of hemolysis, elevated liver enzymes and low platelet count. Obstet Gynecol 2004; 103: 981-991.

2. Martin JN Jr, Rose CH, Briery CM. Understanding and managing HELLP syndrome: the integral role of aggressive glucocorticoids for mother and child. Am J Obstet Gynecol 2006; 195: 914-934.

3. Bergmann F, Rath W. The Differential Diagnosis of Thrombocytopenia in Pregnancy. Dtsch Arztebl Int 2015; 112: 795-802.

4. Barton JR, Sibai BM. Diagnosis and management of haemolysis, elevated liver enzymes and low platelets syndrome. Clin Perinatol 2004; 31: 807-833.

5. Matsuda M, Mitsuhashi S, Watari M, Yamamoto K, Hashimoto T, Ikeda S. Hemolysis, elevated liver enzymes and low platelet (HELLP) syndrome associated with systemic lupus erythemotosus. Intern Med 2003; 42: 1052-1053.

6. Murphy MA, Ayazifar M: Permanent visual deficits secondary to HELLP syndrome. J neuroophtalmol 2005; 25: 122-127.

7. Jebbink J, Wolters A, Fernando F, Afink G, Van der Post J, RisStalpers, C. Molecular genetics of preeclampsia and HELLP syndrome. Biochim Biophys Acta 2012; 1822: 1960. 
8. Karumanchi SA, Maynard SE, Stillman IE, Epstein FH, Sukhatme VP. Preeclampsia: a renal perspective. Kidney Int 2005; 67: 2101-2113.

9. George JN, Nestre CM, McIntosh JJ. Syndromes of thrombotic microangiopathy associated with pregnancy. Hematology Am Soc Hematol Educ Program. 2015; 1:644-8.

10. PoP-Trajković S, Antić V, Kopitović V, Popović J, Trenkić M, Vacić N. Postpartum HELLP syndrome - the case of lost battle. Ups J Med Sci 2013; 118: 51-53.

11. Iwashita Y, Kan'o T, Hattori J, Konno S, Imai H, Kitahara T, Soma K. A case of HELLP syndrome with multiple complications. Intern Med 2012; 51 (16): 2227-2230.

12. Bacak SJ, Thornburg LL. Liver Failure in Pregnancy. Crit Care Clin. 2016; 32: 61-72.

13. Sibai BM. Imitators of severe pre-eclampsia/ eclampsia. Clin Perinatol 2004; 31: 835-852.

14. Cavkaytar S, Ugurlu EN, Karaer A, Tapisiz OL, Danisman N. Are clinical symptoms more predictive than laboratory parameters for adverse maternal outcome in HELLP syndrome? Acta Obstet Gynecol Scand 2007; 86: 648-651.

15. Koenen SV, Huisjes AJ, Dings J, Van der GY, Visser GH, Bruinse HW: Is there a diurnal pattern in the clinical symptoms of HELLP syndrome? J Matern Fetal Neonatal Med 2006; 19: 93-99.

16. Szubert S, Wójcicka K, Gaca M, Linke K, Sajdak S. Jaundice as the first symptom of HELLP syndrome. Ginekol Pol. 2012; 83 (7): 541-544.

17. Hofman-Kiefer KF, Knabl J, Martinoff N, Schiessl B, Conzen P, Rehm M, Becker. Increased serum concentrations of circulating glycocalyx components in HELLP syndrome compared to healthy pregnancy. Reprod Sci 2013; 20: 318-325.

18. Baxter JK, Weinstein L. HELLP syndrome - the state of the art. Obstet Gynecol Surv 2004; 59: 838-845.

19. Quirós C, Suárez F, Prieto B, Rodriguez V, Vaquerizo Ó, Álvarez Menéndez FV. The importance of angiogenic markers in the differential diagnosis of HELLP syndrome vs. non-HELLP thrombocytopenia. Clin Chem Lab Med. 2015; Nov 18.

20. Knapen MF, Mulder TP, Bisseling JG, Penders RH, Peters WH, Steegers EA. Plasma Glutathione S-transferase Alpha I-I: a more sensitive marker for hepatocellular damage than serum alanine aminotransferase in hypertensive disorders of pregnancy. Am J Obstet Gynecol 1998; 178: $161-165$.

21. Deruelle P, Coudoux E, Ego A, Houffin-Debarge V, Codaccioni $\mathbf{X}$, Subtil D. Risk factors for post partum complications occuring after preeclampsia and HELLP syndrome. Eur J Obstet Gynecol Reprod Biol 2006; 125: 59-65.

22. Barton JR, Sibai BM. Diagnosis and management of haemolysis, elevated liver enzymes and low platelets syndrome. Clin Perinatol 2004; 31: 807-833.

23. Jodkowska A, Martynowicz H, Kaczmarek-Wdowiak B, Mazur G. Thrombocytopenia in pregnancy - pathogenesis and diagnostic approach. Postepy Hig Med Dosw 2015; 69: 1215-21.

24. Sibai BM. Imitators of severe pre-eclampsia/ eclampsia. Clin Perinatol 2004; 31: 835-852.

25. Tan A, Ma J, Deng X, Tang G. Severe ascites as the primary symptom of fulminant postpartum HELLP syndrome: a case report. Clin Exp Obstet Gynecol 2015; 42 (5): 685.
26. Myer E, Hill J. First Trimester Hemolysis, Elevated Liver Enzymes, Low Platelets Syndrome in a Surrogate Pregnancy. AJP Rep 2015; 5 (2): 212-4.

27. Le Thi TD, Tieulie N, Costedoat N, Andreu MR, Wechsler N, Vauthier-Brouzes D, Aumaitre $\mathbf{O}$ et al. The HELLP syndrome in the antiphospholipid syndrome: retrospective study of 16 cases in 15 women. Ann Rheum Dis 2005; 64: 273-278.

28. Del-Rio-Vellosillo M, Garcia-Medina JJ. Anesthetic considerations in HELLP syndrome. Acta Anaesthesiol Scand. 2015 Oct 8. doi: 10.1111/ aas.12639.

29. Chou MM, Chen YF, Kung HF, Liu CK, Sun L, Chen WC, Tseng JJ et al. Extensive hepatic infarction in sever preeclampsia as part of the HELLP syndrome: evolution of CT findings and successful treatment with plasma exchange therapy. Taiwan J Obstet Gynecol 2012; 51 (3): 418-420.

30. Wang YQ, Wang J, Ye RH, Yhao YY. Investigation of diagnosis and treatment of hemolysis - elevated liver enzymes- low platelet count (HELLP) syndrome: clinical analysis of 59 cases. Chin Med J (Engl) 2010; 123 (10): 1273-1277.

31. Haddad B, Sibai BM. Expectant management of severe preeclampsia: proper candidates and pregnancy outcome. Clin Obstet Gynecol 2005; 48: 430-440.

32. Oliveira N, Poon LC, Nicolaides KH, Baschat AA. First trimester prediction of HELLP Syndrome. Prenat Diagn. 2015 Sep 24. doi: 10.1002/ pd.4694.

33. O'Brien JM, Barton JR. Controversies with the diagnosis and management of HELLP syndrome. Clin Obstet Gynecol 2005; 48: 460-477.

34. Osmanagaoglu MA, Erdogan I, Zengin U, Bozkaya H. Comparison between HELLP syndrome, chronic hypertension and superimposed preeclampsia on chronic hypertension without HELLP syndrome. J Perinat Med 2004; 32: 481-485.

35. Gul A, Cebeci A, Aslan H, Polat I, Ozdemir A, Ceylan Y. Perinatal outcomes in severe preeclampsia-eclampsia with and without HELLP syndrome. Gynecol Obstet Invest 2005; 59: 113-118.

36. Kim HY, Sohn YS, Lim JH, Kim EH, Kwon JY, Park YW, Kim YH. Neonatal outcome after preterm delivery in HELLP syndrome. Yonsei Med J 2006; 47: 393-398.

37. Stile AD. Prenatal corticosteroids - early gain, long term questions. N Engl J Med 2007; 357: 1248-1250.

38. Whitelaw A, Thoresen M. Antenetal steroids and the developing brain. Arch Dis Child Fetal Neonatal Ed 2000; 83: 154-157.

39. Roberts D, Dalziel S: Antenatal corticosteroids for accelerating fetal lung maturation for women at risk of preterm birth. Cochrane Database Syst Rev 2006; 3: 44-54.

40. Crowther CA, Doyle LW, Haslam RR, Hiller JE, Harding JE, Robinson JS. Outcomes at 2 years of age after repeat doses of antenatal corticosteroids. N Engl J Med 2007; 357: 1179-1189.

41. Wapner RJ, Sorokin Y, Mele L, Johnson F, Dudley DJ, Spong CY, Peaceman AM et al. Long term outcomes after repeat doses of antenatal corticosteroids. N Engl J Med 2007; 357: 1190-1198.

42. Kurtoglu S, Sarici D, Akin MA, Daar G, Korkmaz L, Memur S. Fetal adrenal suppression due to maternal corticosteroid use. J Clin Res Pediatr Endocrinol 2011; 3 (3): 160-162.

43. Basaran A, Basaran M, Sen C. Choice of glucocorticoid in HELLP syndrome - Dexamethasone versus Betamethasone: revisiting the dilemma. J Matern Fetal Neonatal Med 2012; 25 (12): 2597-2600. 
418-424

44. Woudstra DM, Chandra S, Hofmeyr GJ, Dowswell T. Corticosteroids for HELLP syndrome in pregnancy. Cochrane Database Syst Rev 2010; (9): CD008148.

45. Snyder SR, Kivlehan SM, Collopy KT. HELLP Syndrome. How to recognize and treat this life-threatening complication of pregnancy. EMS World. 2015; 44 (6): 39-45.

46. Van Runnard Heimel PJ, Franx A, Schobben AF, Huisjes AJ, Derks JB, Bruinse HW. Corticosteroids, pregnancy and HELLP syndrome: a review. Obstet Gynecol Surv 2005; 60: 57-70.

47. Wallace K, Martin JN Jr, Tam Tam K, Wallukat G, Dechend R, Lamarca B, Owens MY. Seeking the mechanisms of action for corticosteroids in HELLP syndrome. Am J Obstet Gynecol 2013; 208 (5): 380.

48. Martin JN Jr, Thigpen BD, Rose CH, Cushman J, Moore A, May WL. Maternal benefit of high dose intravenous corticosteroid therapy for HELLP syndrome. Am J Obstet Gynecol 2003; 189: 830-834.

49. O'Brien JM, Shumate SA, Satchwell SL, Miligan DA, Barton JR. Maternal benefit of corticosteroid therapy in patients with HELLP syndrome: impact on the rate of the regional anesthesia. Am J Obstet Gynecol 2002; 186: 475-479.

50. Qureshi NS, Tomlinson AJ. Prenatal corticosteroid therapy for elevated liver enzyme/ low platelet count syndrome: a case report. J Reprod Med 2005; 50: 64-66.

51. Fonseca JF, Mendez F, Catano C, Arias F. Dexamethasone treatment does not improve the outcome of women with HELLP syndrome. Am J Obstet Gynecol 2005; 193:1591-1598.

52. Lamer P. Current controversies surrounding the use of repeated courses of antenatal steroids. Adv Neonatal Care 2002; 2: 290-300.
53. Magann EF, Perry KG Jr, Meydrech EF, Harris RL, Chauhan SP, Martin JN Jr. Postpartum corticosteroids: accelerated recovery from the syndrome of hemolysis, elevated liver enzymes and low platelets. Am J Obstet Gynecol 1994; 171 (4): 1154-1158.

54. Schlembach D, Munz W, Fischer T. Effect of corticosteroids on HELLP syndrome - a case report. J Perinat Med 2005; 28 (6): 502-505.

55. Tuzcu ZB, Asicioglu E, Sunbul M, Ozben B, Arikan H, Koc M. Circulating endothelial cell number and markers of endothelial dysfunction in previously preeclamptic women. Am J Obstet Gynecol 2015; 213 (4): 533.

56. Drakeley AJ, Le Roux PA, Anthony J, Penny J. Acute renal failure complicating severe preeclampsia requiring admission to an obstetric intensive care unit. Am J Obstet Gynecol 2002; 186: 253-256.

57. Mao M, Chen C. Corticosteroid therapy for management of Hemolysis, Elevated Liver Enzymes, and Low Platelet Count (HELLP) syndrome: A meta-analysis. Med Sci Monit 2015; 21: 3777-83.

58. Isler CM, Magann EF, Rinehart BK, Terrone DA, Bass JD, Martin JN Jr. Dexamethasone compared with betamethasone for glucocorticoid treatment of postpartum HELLP syndrome. Int J Gynaecol Obstet 2003; 80: 291-297.

59. Katz L, Amorim M, Souza JP, Haddad SM, Cecatti JG. COHELLP: collaborative trandomized controlled trial on corticosteroids in HELLP syndrome. Reprod Health 2013; 22: 10-28.

60. Šimetka O, Vlk R, Procházka M. HELLP syndrom. Maxdorf Jessenius; 2013. 93-97.

61. Bayraktaroglu Z, Demirici F, Balat O, Kutlar I, Okan V, Ugur G. Plasma exchange therapy in HELLP syndrome. Turk J Gastroenterol 2006; 17: 99-102. 